\title{
Antibacterial Effects of Amino Acids-grafted Water-soluble Chitosan against Drug-resistant Bacteria
}

\author{
Jun-Ho Kim, Nam-Hong Kim, Eun-Ji Kim, Ji Ho Kim, Min-Young Lee, Yung-Hoon Park, Jung Ro Lee, \\ Seong-Cheol Park, and Mi-Kyeong Jang
}

Received: 28 January 2016 / Accepted: 21 February 2016

(C) The Korean Society for Biotechnology and Bioengineering and Springer 2016

In the 2016 issue of Biotechnology and Bioprocess Engineering (BBE), an error occurred in the research article: Jun-Ho Kim, Nam-Hong Kim, Eun-Ji Kim, Ji Ho Kim, Min-Young Lee, Yung-Hoon Park, Jung Ro Lee, Seong-Cheol Park, and Mi-Kyeong Jang (2016) Antibacterial Effects of Amino Acids-grafted Water-soluble Chitosan against Drug-resistant Bacteria. Biotechnol. Bioprocess Eng. 21: 183-189.
- On page 188, left column, the Fig. 4 should be replaced by:
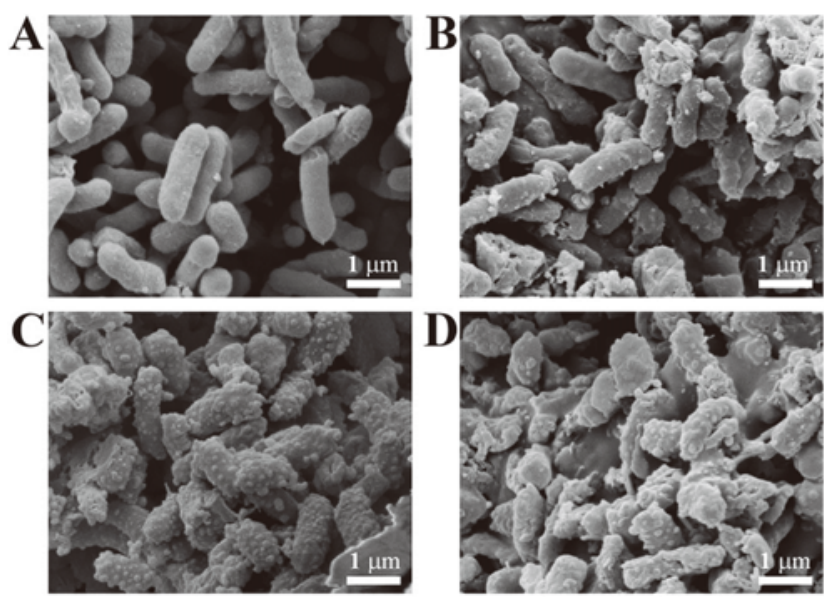

This error does not change the scientific conclusions of the article in any way. The authors apologize for this error.

Jun-Ho Kim ${ }^{\dagger}$, Nam-Hong Kim ${ }^{\dagger}$, Eun-Ji Kim, Ji Ho Kim, Yung-Hoon Park, Seong-Cheol Park*, Mi-Kyeong Jang*

Department of Polymer Science and Engineering, College of Engineering, Sunchon National University, Suncheon 540-950, Korea

Tel: +82-61-750-3567; Fax: +82-61-750-3508

E-mail: jmk8856@sunchon.ac.kr

Tel: +82-61-750-5421; Fax: +82-61-750-3508

E-mail: schpark9@gnu.ac.kr

Min-Young Lee

Department of Microbiology, School of Medicine, Gyeongsang National University, Jinju 660-750, Korea

Jung Ro Lee

National Institute of Ecology, Seocheon 325-813, Korea

${ }^{\dagger}$ First two authors have contributed equally to this work. 